\title{
Intention Toward Acceptance of Online Shopping Among Consumers in Kano, Nigeria: Application of UTAUT Model Approach in A Nigerian Context
}

\author{
Usman Muhammad Umar \\ Research Scholar, Mittal School of Business, Lovely Professional University (LPU), India \\ Adamkolo Mohammed Ibrahim* \\ Lecturer and Research Scholar, Department of Mass Communication, University of Maiduguri, PMB 1069, \\ Borno State, Nigeria; PhD Candidate, Bayero University, Kano, PMB 1130, Kano State, Nigeria
}

\begin{abstract}
The research was financed by Asian Development Bank. No. 2006-A171(Sponsoring information)
Abstract

Interestingly, the internet has become one of the most significant and popular platforms for businesses to market their offerings throughout the world. Shopping through the internet has emerged in recent years as a new concept and is advancing in many countries around the world, including sub-Saharan Africa such as Nigeria. However, the acceptance of e-shopping faces many challenges and barriers, such as technological, cultural, organisational, personal and social issues, which must be addressed for improved acceptance by consumers. Using a qualitative approach with a modified version of the UTAUT2 model (by integrating 'awareness of online shopping' and 'mobile skilfulness'), the focus of this paper is to explore the critical factors influencing consumer behavioural intention towards the acceptance of online shopping based on the UTAUT model approach. Purposive sampling technique was employed to select a sample of 17 participants. Focus group interview was conducted with Nigerian postgraduate students of Lovely professional university India. The findings suggest that performance expectancy, effort expectancy, social influence, awareness of online shopping and mobile skilfulness are the major factors that are likely to influence behavioural intention to accept online shopping in Nigeria. The result of this study will be beneficial for policy makers/government agencies, telecommunication companies as well as online stores.
\end{abstract}

Keywords: Behavioural intention, Consumer, Internet shopping, Online shopping in Nigeria, UTAUT

DOI: $10.7176 / \mathrm{JAAS} / 64-01$

Publication date:May $31^{\text {st }} 2020$

\section{Introduction}

Nowadays, the application of ICT has become almost inevitable in businesses all over the world (Ibrahim, Hassan $\&$ Pate, 2016). The internet has become one of the most important and popular platforms for businesses to market their goods and services worldwide (Leeflang, Verhoef, Dahlström \& Freundt, 2014; Mokhtar, 2015). Interestingly, the recent development in information and communications technology (ICT) and their application has presented great opportunities for businesses to promote their marketing capabilities (Taiminen \& Karjaluoto, 2015; Maduku, Mpinganjira \& Duh, 2016).

The Global Retail Electronic Commerce Index (GRECI) reports that e-retailing is continuously rising globally. In 2017, retail e-commerce sales worldwide amounted to $\$ 2.3$ trillion. The Index forecasts that global e-retail revenues will increase to $\$ 4.88$ trillion by the year 2021 (GRECI, 2017). In the context of Asia Pacific, India has the largest number of internet users, and is ranked the third largest internet user in the world (Kumar \& Bajaj, 2016). These trends demonstrating the increase growth of e-retailing indicate the importance of how consumers view online shopping. Further, the United Nations Conference on Trade and Development (UNCTAD) ranks 152 countries globally, including 44 African nations by measuring their readiness for online shopping. Nigeria, South Africa and Kenya accounted for nearly half of Africa's estimated 21 million online shoppers in 2017 and the continent's consumer e-commerce market, which was valued at \$5.7 billion in 2017 (UNCTAD, 2017). The World Bank Doing Business report indicates that Mauritius was the highest ranked African nation in the index in 2018 while Nigeria, being the continent's largest e-commerce market (by shoppers' population and revenue) was ranked second highest with South Africa coming third (digestafrica.com, 2018).

The online purchasing behaviour of consumers has in recent times became a topic of increased interest and attention for researchers, marketers and policy makers (Celik, 2016). Nonetheless, due to its complexity, this phenomenon is still in its infancy in many developing nations such as Nigeria and therefore, requires more attention (Rahman \& Iqbal, 2017; Auf, Meddour, Saoula \& Majid, 2018). To understand the phenomenon of online shopping, it is imperative to have a good understanding about the factors that affect consumers' online purchasing behaviour (Ibrahim, Hassan, \& Yusuf, 2018).

Shopping through the internet continues to increase significantly, especially in developed nations. Unlike developing countries, online shopping has not received enough attention and support because, probably, people in 
these countries are slow to accept such advance technology as the features of the new technology are unfamiliar and appear insecure and full of risks (Faqih, 2016; Rahman, Khan \& Iqbal, 2017; Farah, Hasni \& Abbas, 2018). Additionally, there are challenges and limitations associated with these technologies in developing country contexts. Among those technological and non-technological issues include internet accessibility and speed, lack of awareness, computer literacy, cultural barrier, risk and trust, social and demographic issues, security and privacy dilemmas, technological know-how, cost, language barriers, low internet infrastructure, inadequate regulatory framework and consumers negative attitude (Abiodun, 2013; Agwu, 2014; Kabanga \& Aso, 2015; Okoyi \& Obi, 2015; Abu Shamaa \& Abu Shanab, 2015; Faqih, 2016; Rahman, Khan \& Iqbal, 2018).

Most of these issues have been attributed to virtually slow down the development of online shopping in developing countries (Faqih, 2016). However, there exists a knowledge gap on what factors affecting the behavioural intention of consumers on the acceptance of electronic shopping in developing cultures such as Nigeria. Also, emerging markets have diverse institutional contexts especially in terms of socio-economic and regulatory aspects. Furthermore, the theories and models developed in advanced, Western nations need to be validated and adjusted to suit various, non-Western cultures (Tandon, Kiran \& Sah, 2016).

In this regard, the present study aims to assess the factors that may affect consumer behavioural intention towards e-shopping by adopting a modified version of the Unified Theory of Acceptance and Use of Technology (UTAUT). We incorporated two external constructs, namely awareness and mobile skilfulness as additional variables. These two constructs are very are expected to measure factors associated with uncertainty surrounding e-shopping in a Nigerian context. Further, cultural values and gender were also integrated in the model to serve as moderators as done in past studies (e.g., Celik, 2016; Faqih, 2016; Rahman, Khan \& Iqbal, 2017; Saprikis, Saprikis, Markos, Zarmpou \& Vlachopoulou, 2017; Tandon, Kiran \& Sah, 2017). The UTAUT model is proven to be more powerful and able to describe the disparity in the acceptance of technology better than Technology Acceptance Model (TAM) as well as any other technology acceptance theoretical models (Al-Momani, Mahmoud \& Ahmad, 2019). The model adopted in this study can be applied in various domains and regions to understand customer acceptance of online shopping (Adamu, Ibrahim, \& Lawan, 2019). The objective of this study was to gain an insight and better understanding on the factors influencing the acceptance of online shopping among consumers in Kano State, Nigeria using a modified UTAUT model approach, with two additional constructs namely, Technology awareness and mobile skilfulness.

The study is organized as follows. First, the review of the literature, which comprises sub-sections on the concept of online shopping, the theoretical model of the factors affecting that influence consumers towards acceptance of online shopping, the conceptual framework and an empirical review on the various variables of the modified UTAUT model. The second section discusses the research methodology employed in this study. The third section discusses the findings of the study. Finally, the fourth section discusses the concluding remarks and recommendations.

\section{Review of Literature}

\subsection{The Concept of Online Shopping Concept}

Online shopping has different meanings, which are used interchangeable. These meanings are electronic shopping, internet shopping, e-shopping and web shopping (Aminu, 2013). Electronic commerce, particularly e-shopping is becoming gradually popular in the world. Online shopping may be described as activities involving searching, purchasing and selling goods and services online. It involves all purchasing activities on the internet which range from information search to actual purchase (Omotayo \& Adeyemi, 2018). Some of the potential benefits of eshopping for consumers are convenience, low price, saving time, various selection, personal attention, easy access to product information, 24 hours facilities, and original services among others (Niedermeier, Wang, \& Zhang, 2016).

Past studies showed that Nigeria has been one of the fastest growing nations in the world in terms of information and communication technology (ICT) with the introduction of global system for mobile communication in the year 2001, yet online purchase did not gain ground until 2012 (Omotayo \& Adeyemi, 2018). In Nigeria, the number of internet clients has additionally risen exponentially since the rise and accessibility of cell phones and information technology in the nation. According to Nigerian Communication Commission (NCC) cited in Internet World Statistics (IWS, 2017), the country has a population of nearly 192 million, out of which 92 million people are internet users (which represent $47.9 \%$ of the population by December 2016). This is an indication that Nigeria has the potential to become an online shopping hub in Africa (Ibrahim et al., 2018a).

Despite online shopping is still growing in Africa, especially in Nigeria (Çelik, 2011), consumers can shop online from local, regional and even global online stores. However, there have been a substantial number of literatures published on the factors affecting the adoption and use of internet technology. Reviews of past studies indicate that different models and variables influenced consumer behavioural intention towards e-shopping in different countries with emphasis of the area of study Nigeria. 


\subsection{Theoretical Review and the Research Model}

The conceptual framework of this study was designed based on the UTAUT theoretical model, as mentioned earlier, which is the underlying theory of the study. Previous literature on consumer perception and behavioural intention towards online shopping was critically reviewed and found that the model is relevant to explain and predict the problem under study. The model was formulated and validated by Venkatesh et.al (2003) from the integration of elements of eight prominent models connected to the topic after empirical comparison between them. Those eight models are Theory of Reason Action (TRA), Technology Acceptance Model (TAM), Motivational Model (MM), Theory of Planned Behaviour (TPB), Combined TAM and TPB (C-TAM-TAB), Model of PC Utilisation (MPCU), Innovation Diffusion Theory (IDT), and Social Cognitive Theory (SCT). The above theories and models have been widely accepted and applied in order to explain technology adoption (Taiwo \& Downe, 2013).

The UTAUT model utilises four key determinants of technology adoption intention and use, namely performance expectancy, effort expectancy, social influence and facilitating conditions. Four moderators, namely gender, age, experience and voluntariness of use moderated the connection paths in the model (Taiwo \& Downe, 2013). Many scholars have concentrated on the various technology acceptance model and incorporated one or two additional constructs as well as one or two moderating variables that influence the key determinants of behavioural intention and made conclusion as regards the factors affecting the acceptance of the new technology in diverse context (Niedermeier et al., 2016).

However, UTAUT aims to examine any technological innovation acceptance and usage in customers' point of view. This diverse body of work has seen many new constructs being unified into the original theory (Hoehle \& Venkatesh, 2015). The model has some limitations as an analysis of acknowledged limitations across studies pointed out that concentrating on a single subject in terms of a country, community, organization, department, agency, individual, or age group was the most widespread reported drawback. Hence, the researchers decided to examine the applicability of the modified version of the model in a Nigerian context. Because of the model's limitations, there is need to explore variables that can enhance the model and measure the diverse dimensions of technology acceptance also measure the impact of external factors on the model (Alan \& Barua, 2018).

Although there are various theories and models of technology adoption, the application of UTAUT in technology adoption research has been popular due to its ability to explain the users' and behaviour (Mohamad \& Kassim, 2018). UTAUT is a comprehensive model that described roughly $70 \%$ of the variance in behavioural intention in technology acceptance and usage (Venkatash, 2012). Many studies confirmed the acceptability of UTAUT model in e-commerce context (Abubakar \& Ahmad; Tarhini, Masa'deh, Al-Busaidi, Mohammed \& Maqableh, 2017; Celik, 2016; Abrahao, Moriguchi \& Andrde, 2016 Samadi \& Hakimiyan, 2017; Mohamad \& Kassim, 2018; Dwivedi, 2018; Cao \& Niu, 2019). But majority of the studies that used UTAUT model have been conducted in developed countries and have not been widely tested in developing countries such as Nigeria.

\subsection{The Conceptual Framework}

The conceptual framework of this study was designed based on a modified version of the UTAUT model. As part of the modifications, all the four moderator variables were dropped and two predictor variables (technology awareness and mobile skilfulness) were incorporated. Only predictor variables were computed; thus, making the number of predictors be six. Therefore, in order to fill this gap, this study applied the original UTAUT model with two additional factors. Given the multifaceted environment, cultural and religious influences as well as social paradigm in developing countries like Nigeria, we accepted awareness of online shopping and mobile skilfulness as two additional variables that significantly influence consumers' behavioural intention to shop online in Nigeria. In support, the findings of Adamkolo, Hassan \& Gusau (2018) recommends that those four expectancies of UTAUT model namely (PE, EE, FC \& SI) alone may not likely to account for the numerous factors influencing ICT use in a global context. Hence, some modifications are made. The conceptual framework of the study, which is the modified UTAUT model is shown in Figure 1.

\subsection{Empirical Review - The Unified Theory of Acceptance and Use of Technology}

2.4.1 Performance expectancy

This is seen as the degree to which an individual believes that using the system will benefit him/her to attain gains in job performance (Venkatesh et al., 2003). The constructs that are related to performance expectancy in the previous theories and models include perceived usefulness of theory of acceptance model (TAM), relative advantage in innovation diffusion theory (IDT), job fit in task technology fit model (TTF), extrinsic motivation in the motivation model (TMM) and outcome expectancy in social cognitive theory (SCT). Empirical evidence from prior studies confirmed that gender and age play a vital moderating effect on the influence of performance expectance on behavioural intention (Abubakar \& Ahmad, 2013). In their study, Carlson et. al. (2006) exposed that PE has direct effect on intention to use mobile phones. Agwu and Carter (2014) revealed that performance expectance significantly influenced people to use mobile services. Similarly, in a study by Tarhini et al. (2017), PE was found the strongest precursor of behavioural intention to use internet banking. Adamkolo, Hassan \& 
Gusau (2018) found that PE significantly influenced technology innovation use. This signifies that PE may have significant role in individual behaviour for accepting or rejecting online shopping in Nigeria. As such, in the context of this study, it is expected that if the Nigerian consumers discover that shopping through the internet is useful, then they will accept and use the system.

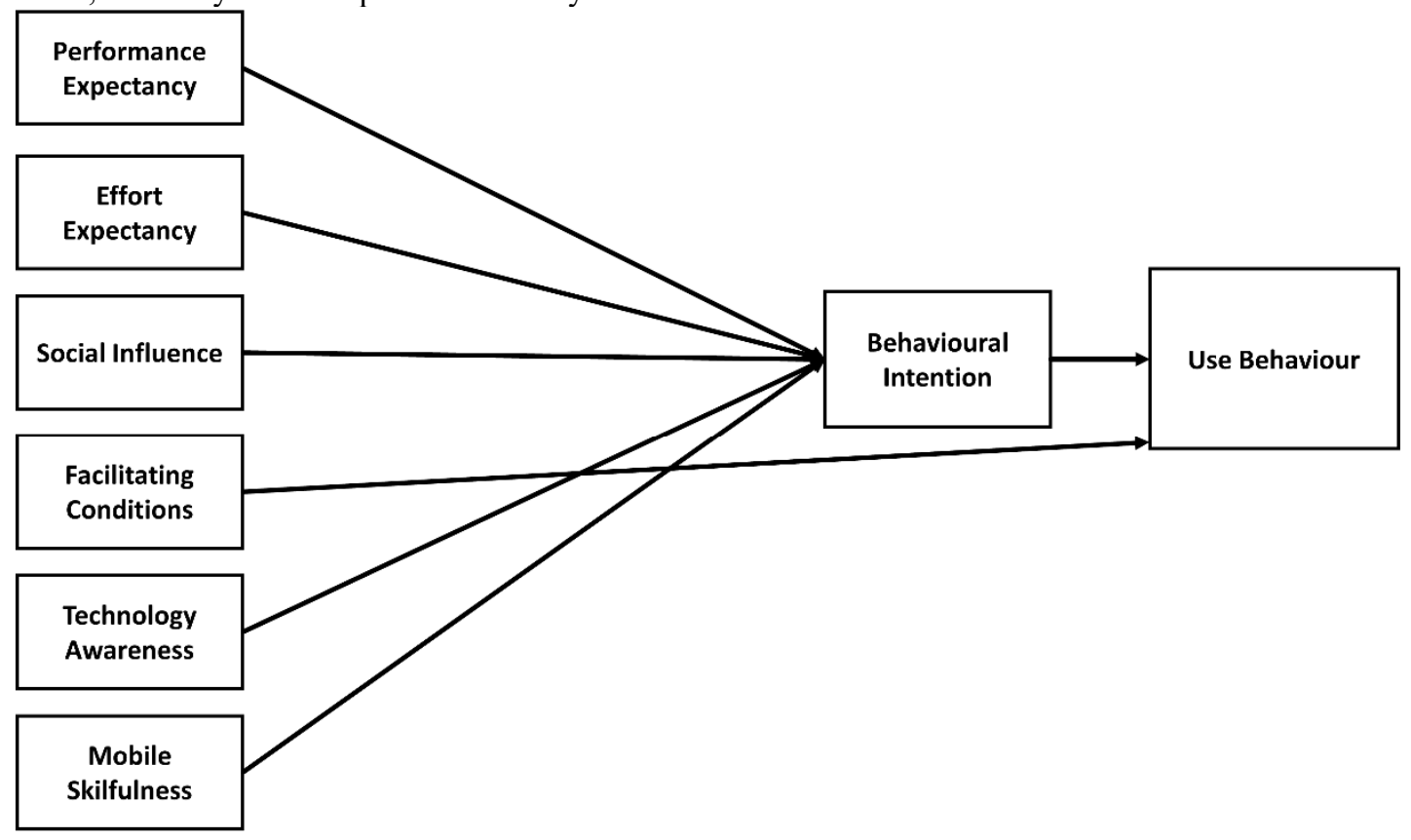

Figure 1: The conceptual framework of this study, which is the modified UTAUT model (Adapted from Venkatash et al., 2003).

\subsubsection{Effort expectancy}

Users tend to consider the effort required before using the information system. EE is the degree of ease associated with the customers' use of technology (Venkatesh et al., 2003). The construct was originated from technology acceptance model (TAM) as perceived ease of use, innovation diffusion theory (IDT) and model of PC utilisation (MPCU) as complex. In their perspective, Venkatash et al. (2003) reported that evidences from previous literature revealed that the influence of effort expectancy on behavioural intention is stronger in older employees and young women, therefore they hypothesised age, gender and experience to moderate the association between the constructs. EE explains users' opinion of the efforts associated with the use of a technology and customers' benefits differ about the kind of click and collect model as well as the age of users (Venkatesh et al., 2003). According to Alalwan, Baabdullah, Rana, Tamilmani \& Dwivedi (2017); Alam \& Barua (2018) users feel connected to technologies that are convenient and simple to use. The easy accessibility of a technology may likely inspire users, making them highly inclined to adopt the technology (Dwivedi, Rana, Jeyaraj, Clement \& Williams, 2017).

2.4.3 Social influence

SI means the social pressure coming from external environment which surrounds the persons and may influence their perceptions and behaviours towards engaging in a certain action such as the opinion of friends, family, colleagues and relatives (Tarhini, 2017). This construct is the same with subjective norms in theory of reason action TRA, TAM, TPB, and C-TAM-TPB. Technology adoption such as the use of online shopping are often significantly influenced by social influence (Celik, 2016; Tarhini, 2017). Adoption of new technology greatly depends not only on an individual belief but also on social influence (Yang et al., 2009). Past studies on e-shopping acceptance have presented consistent outcomes on the effect of social norms on user intentions (Yang, 2010; Slade, Dwivedi, Piercy \& Williams, 2015; Celik, 2015). Additionally, Alam \& Barua (2018) stated that social influence factors like affiliation and perceived popularity of a new technology, also have an influence on behavioural intention.

2.4.4 Facilitating condition

FC is a variable that is like perceived behavioural control and compatibility in TPB and IDT. According to Venkatash et al. (2003) facilitating condition variable is defined as "the degree to which an individual believes that an organisational and technical infrastructure exists to support use of a system”. In other words, facilitating condition refers to the state at which all the required facilities, equipment, tools, and assistance are provided to an individual in order to support the use of a system (Kabir, Saidin \& Ahmi, 2017). It is believed that online shopping requires a particular skill, resources and technical infrastructure but these resources are not usually free at customer context (Adamu et al., 2018; Niedermeier et al., 2016). Online shopping as a significant service requires the user 
to have the latest technology to use the system (Tarhini et al., 2017).

According to Celik (2016), FC entails certain elements (for example personal assessment about the knowledge adequacy as well as assistance availability for technology use). Thus, FC has been conceiving through the combination of both internal and external support aspects in UTAUT. As such, online shopping has related requirements for the existence of knowledge, resources and support allowing the customer to overcome certain limitations, such as the lack of tangible shopping experiences, the absence of direct personal contact with sales representatives, interactions with checkout interfaces instead of clerks and the need for shipment tracking (Celik, 2016). Therefore, in the context of the present study, FC will be measured by the perception of buyers if they are able to access the required resources and the necessary support to shop online or not. And so, it is assumed that these external resources will influence the shoppers to accept online shopping system (Tarhini, 2017).

2.4.5 Technology awareness

According to Mofleh, Wanous and Stracham (2008), technology awareness is defined as "citizen's knowledge about the existence and benefits of technology". The perception of awareness was originally used in the early phase of an innovation diffusion theory (IDT) proposed by Bagozzi, P \& Yi (1989). Afterwards IDT has been used in studies related to technology usage where the positive effect of awareness on attitude towards technology has been confirmed (Alaeddin \& Altounjy, 2018). Hence, the first stage in consumer behaviour is the consumer awareness about anything which leads to develop interest and followed by other stages in buying process (Ansari \& Alhazemi, 2016).

In his analysis of acceptance process Kiwanuka (2015) noted that awareness stage is significant before the adoption of any technology. In support of this, Bamberg \& Moser (2007) suggested that is a key requirement for the development of moral norm, unluckily there is lack of awareness in developing nations, particularly in respect of e-government services (Rehman, Esichaikul \& Kamal, 2012). Past studies discovered that technology awareness significantly influenced the adoption of electronic payment systems (Rehman, Esichaikul \& Kamal, 2012; Abubakar \& Ahmad, 2013). Since e-commerce is emerging as a new concept in the case study area, the required awareness is still low, so there is need for an increase awareness. There has been calls by many researchers on the need to create awareness on the acceptance and usage of e-commerce (Chiemeka \& Evwiekpaefe, 2011; Ibrahim et al., 2018b; Sylvester, Akpan \& Akang, 2016). Based on the above views about the usefulness of awareness on the adoption of e-commerce adoption, this study incorporated UTAUT constructs with technology awareness as one of the major variables to influence consumer behavioural intention towards the acceptance of e-shopping in Nigeria. It is believed that if there is awareness, e-shopping acceptance and usage level will also increase.

2.4.6 Mobile skilfulness

There exist many studies that investigated skilfulness as a substantial factor in influencing users' behaviour towards a specific technology (e.g. Fagan, Neil \& Wooldridge, 2003; Davis \& Vladica, 2005 in Saprikis et al.2018) $\mathrm{Lu}$ and $\mathrm{Su}$ (2009) strongly suggested that skilfulness should be observed as a driving factor in the area of mobile commerce. Skilfulness in this study refers to the individual's assessment of his/ her ability to buy online using a mobile device. However, it is accepted that the greater mobile user's capability belief the greater the chances to accept and use mobile devices to purchase online (Saprikis et al.2018). For example, several studies found that the greater the user's capability belief the greater user's intrinsic (Deng, Doll \& Truong, 2004; Lu \& Su, 2009 cited in Saprikis et al, 2018). On the contrary, other researches have confirmed that people feel anxiety in their attempt to achieve particular behaviours that they do not accomplish skilfully (Niedermeier et al., 2016). Therefore, it is important to understand the potential impact of mobile skilfulness as one of key factor influencing the acceptance of e-shopping in Nigeria.

\section{Material and Methods}

\subsection{The Research Design}

This study used a qualitative research method of focus group interview. A qualitative research approach is also suitable in understanding perceptions of respondents, important phrases which sum up experiences of the respondents and find their reasons behind a decision (Jadhav \& Khanna, 2016). According to Robinson (1999, p.905) cited in Olaleye, Ukpabi, Karjaluoto \& Rizomyliotis (2018), a focus group is "an in-depth, open-ended group discussion of 1-2 hours duration that explores a specific set of issues on a predefined and limited topic. Such group consist typically of between five and eight participants and are convened under the guidance of a facilitator". Usually focus group discussions involve 4 to 12 participants, the exact number depending upon the number of the participants, the topic matter as well as the expertise of the interviewer (Saunders, Lewis \& Thornhill, 2016).

\subsection{Sampling, Procedures and Data Analysis}

The study employed purposive sampling to select the participants. The study sample involves some selected Nigerian postgraduate students of Lovely Professional University (LPU) in India. All the selected participants hail from Kano State, Nigeria and had shopped online at least once in the previous three months in Nigeria (which is one of the criteria for selecting the participants). All selected focus group members belong to the academia as civil 
servant and have some knowledge and experience of online shopping. The focus group interviews were conducted on one-to-one basis with each group member in the university premises. The moderator introduced himself as well as the topic for discussion to group members. The participants then discussed freely by sharing their experiences with online shopping.

All documents for recording the data for the research were considered and the statements were coded in accordance with the themes. The themes were also determined from the literature review as well as the four constructs of the original UTAUT model (performance expectancy, effort expectance, social influence and facilitating conditions) including the two additional factors namely awareness and mobile skilfulness. In doing so, we noticed differences in the participants' opinions. Six themes were identified from the interview based on the UTAUT constructs. The questions in the interview guide also covered the points which helped in getting an idea of the factors influencing the online purchase behaviour of the Nigerian consumers. The data obtained from the focus group interview were analysed using qualitative content analysis.

\section{Results and Discussion}

The focus group interview participants were all male aged between 35 to 45 years. All questions and responses were recorded. Interview findings are arranged based on the series of questions raised during the interview.

Performance expectancy refers to "the degree to which using a technology will provide benefits to the consumers in performing certain activities" (Venkatash et al., 2012). Most of the participants (seven out of eight) have positive views about online shopping for its convenience, flexibility, privacy, time saving, speed, pleasure, and availability of products online. Thus, studies have shown that performance expectancy has a significant impact on buying intention (Venkatash, 2003, Tarhini et al., 2017; Kazancoglu \& Aydin, 2018). However, one participant claimed negative statement as online shopping as risky.

Effort expectancy is the degree of ease associated with the customers' use technology, which affects purchase intention" (Venkatash et al., 2012). Most of the participants (six out of eight) acknowledged that shopping through the internet is easier. On the other hand, two participants stated that online shopping do not provide ease of use for the following reasons:

Mistakes are more likely to happen, sometimes internet connectivity is fluctuating, anxiety about the delivery of the product, problem with payment system.

In addition, one of the two participants reports that," online shopping in Nigeria is meant for educated people".

Social influence is the degree to which an individual perceives that important others believe he/she should use the system (Venkatesh et al., 2012). Five of the participants agreed that it is the "influence of their friends and colleagues in the work place" that inspired them to accept internet shopping. Whereas the remaining three stated that it is fashion to shop online.

According to Venkatash et al. (2003) facilitating condition variable is defined as "the degree to which an individual believes that an organisational and technical infrastructure exists to support use of a system". The participants unanimously believed that improving the security would make online shopping more secured which in turn may increase its acceptance among Nigerians. The respondents also comment that "improving the infrastructures development" will encourage more people to embrace the system. One participant noted that there was a "delivery problem" as majority of the online retailers outside Nigeria cannot deliver goods to Nigeria.

According to Mofleh, Wanous \& Stracham (2008), technology awareness is defined as "citizen's knowledge about the existence and benefits of technology". Hence, for a system to work properly there is a great need for its awareness. All the participants are aware about online shopping. However, the participants emphasised on the need to "create awareness by sensitizing the consumers and the general public" about the potential benefits of online shopping. The participants argue that the government in collaboration with the e-retailers and mobile telecommunication companies as well as other internet service providers should put more effort in enlighten campaign to let people know its benefits. Therefore, gaining consumers' awareness is highly crucial for a high acceptance of online shopping in Nigeria as many Nigerians are still not aware about its benefits.

Skilfulness in this study refers to the individual's assessment of his/ her ability to buy online using a mobile device. However, it is accepted that the greater mobile user's capability belief the greater the chances to accept and use mobile devices to purchase online (Saprikis et al., 2018). It has been acknowledged that expertise in how to use a technology or part of an information system is vital for optimizing its benefits (Olaleye et al., 2018). All the participants have expertise and knowledge on how to use their mobile device to buy online.

\section{Conclusion and Recommendations}

The findings of the study were extracted from the focus group interview that explored the factors influencing the acceptance of online shopping among consumers in Nigeria. The objective of this study was to gain an insight and better understanding on the factors influencing the acceptance of online shopping among Nigerians through the extension of UTAUT model with two additional factors namely: technology awareness and mobile skilfulness. So, by extending UTAUT to include these two factors will provide more comprehensive theoretical perspective of 
user technology acceptance in the context of e-shopping. Similar, adding awareness and mobile skilfulness will complement the existing factors of the UTAUT and is expected to provide a better prediction of consumers' acceptance of online shopping in Nigeria. The key findings cited by majority of the participants of this study are that convenience, internet accessibility, security, delivery and awareness are found to have the highest influence on consumer behavioural intention to use online shopping. Thus, the issue of awareness requires a great concern and its advised that online retailers should emphasise on educating consumers on the benefits of such a new system.

The key findings cited by majority of the participants of this study are that convenience, internet accessibility, security, delivery and awareness are found to have the highest influence on consumer behavioural intention to use online shopping. Thus, the issue of awareness requires a great concern and its advised that online retailers should emphasise on educating consumers on the benefits of such a new system.

Finally, the participants provide the following recommendations:

- There is need increase creation of awareness among Nigerian consumers.

- Government should invest heavily on IT.

- Infrastructures development should be improved.

- Payment on delivery of goods should be encouraged.

- Government should encourage IT training in schools.

- There is need for Islamic scholars to make clear to consumers regarding e-commerce from Islamic perspective.

\subsection{Limitations and Recommendations for Further Research}

As with any study, our research has some limitations that need to be identified and deliberated. Firstly, this study was limited to focus group interviews held by only postgraduate students. Secondly, our sample frame is relatively small which is considered one of the main weakness of using qualitative approach (Bryan \& Bell, cited in Tarhini et al., 2017). As such, generalisation of the findings should be treated with caution. Also, the findings of our study can be used by the researchers as a foundation in the application of further exploratory research in the context of online purchase behaviour in the study area.

\section{References}

Abubakar, F. M., \& Ahmad, H. B. (2013). The moderating effect of technology awareness on the relationship between UTAUT constructs and behavioural intention to use technology: A conceptual paper. Australian Journal of Business and Management Research, 3(2), 14-23.

Adamu, M. A., Ibrahim, A. M., \& Lawan, A. K. (2018). Let's go 'shoppie' — Social media shopping's cool! Nigerian students' acceptance of online shopping via social media. New Media and Mass Communication, 77. doi: 10.7176/NMMC

Agwu, M. E. \& Carter, A. L. (2014). Mobile phone banking in Nigeria: Benefits, problems and prospects. International Journal of Business and Commerce, 3(6), 50-70.

Al-Momani, A. M., Mahmoud, M. A., \& Ahmad, M. S. (2019). A Review of factors influencing customer acceptance of internet of things services. International Journal of Information Systems in the Service Sector, 11(1), 54-67. doi: 10.4018/ijisss.2019010104

Aminu, S. A. (2013). Challenges militating against adoption of online shopping in retail industry in Nigeria. Journal of Marketing Management, 1(1), 23-33.

Aldousari, A. A., Delafrooz, N., Ab Yajid, M. S., \& Ahmed, Z. U. (2016). Determinants of consumers' attitudes toward online shopping. Journal of Transnational Management, 21(4), 183-199. doi: 10.1080/15475778.2016.1226658

Alalwan, A. A., Baabdullah, A. M., Rana, N. P., Tamilmani, K., \& Dwivedi, Y. K. (2018). Examining adoption of mobile internet in Saudi Arabia: Extending TAM with perceived enjoyment, innovativeness and trust. Technology in Society, 55, 100-110.

Auf, M. A. A., Meddour, H., Saoula, O., \& Majid, A. H. A. (2018). Consumer buying behaviour: the roles of price, motivation, perceived culture importance, and religious orientation. Journal of Business and Retail Management Research, 12(4), 19-33.

Bashir, A. M., Bayat, A., Olutuase, S. O., \& Abdul Latiff, Z. A. (2019). Factors affecting consumers' intention towards purchasing halal food in South Africa: A structural equation modelling. Journal of Food Products Marketing, 25(1), 26-48.

Cao, Q., \& Niu, X. (2019). Integrating context-awareness and UTAUT to explain Alipay user adoption. International Journal of Industrial Ergonomics, 69, 9-13. doi: 10.1016/j.ergon.2018.09.004

Dwivedi, Y. K., Rana, N. P., Jeyaraj, A., Clement, M., \& Williams, M. D. (2017). Re-examining the Unified Theory of Acceptance and Use of Technology (UTAUT): Towards a revised theoretical model. Information Systems Frontiers, 2(11), 79-99. doi: 10.1007/s10796-017-9774-y

Faqih, K. M. S. (2016). An empirical analysis of factors predicting the behavioural intention to adopt Internet 
shopping technology among non-shoppers in a developing country context: Does gender matter? Journal of Retailing and Consumer Services, 30, 140-164. doi: 10.1016/j.jretconser.2016.01.016

Farah, M. F., Hasni, M. J. S., \& Abbas, A. K. (2018). Mobile-banking adoption: empirical evidence from the banking sector in Pakistan. International Journal of Bank Marketing, 9(7), 77-90. doi: 10.1108/ijbm-10-20170

Ibrahim, M. A., Hassan, M. S., \& Pate, A. U. (2018a). Consumers' demographic factors influencing perceived service quality in e-shopping: Some evidence from Nigerian online shopping. Pertanika Journal of Social Sciences \& Humanities, 26(3), 135-1369.

Ibrahim, A. M., Hassan, M. S., \& Yusuf, S. (2018b). Factors determining e-shopping compliance by Nigerians. In Khosrow-Pour, M. (Ed.). Encyclopedia of information science and technology, $4^{\text {th }}$ edition. Hershey, PA: IGI Global, pp. 2761-2772.

Internet World Statistics (2017). Use and population statistics: Africa: Nigeria internet and telecommunications reports. http://www.internetworldstats.com/africa.html

Isohella, L., Oikarinen, E. L., Saarela, M., Muhos, M., \& Nikunen, T. (2017). Perceptions of digital marketing tools in new microenterprises. In Management Challenges in a Network Economy: Proceedings of the MakeLearn and TIIM International Conference (pp. 85-95).

Izogo, E. E., \& Jayawardhena, C. (2018). Online shopping experience in an emerging e-retailing market: Towards a conceptual model. Journal of Consumer Behaviour, 17(4), 379-392. doi: 10.1002/cb.1715

Kabir, M. A., Saidin, S. Z., \& Ahmi, A. (2017, October). An extension of technology acceptance model to determine factors that influence the intention to use electronic collection system in Nigerian federal hospitals. In AIP Conference Proceedings (Vol. 1891, No. 1, p.020072). AIP Publishing.

Kumar, P., \& Bajaj, R. (2016). Dimensions of perceived risk among students of high educational institutes towards online shopping in Punjab. The Journal of Internet Banking and Commerce, 21(3), 98-108.

Leeflang, P. S., Verhoef, P. C., Dahlström, P., \& Freundt, T. (2014). Challenges and solutions for marketing in a digital era. European Management Journal, 32(1), 1-1.

Maduku, D. K., Mpinganjira, M., \& Duh, H. (2016). Understanding mobile marketing adoption intention by South African SMEs: A multi-perspective framework. International Journal of Information Management, 36(5), 711-723.

Mokhtar, N. F. (2015). Internet marketing adoption by small business enterprises in Malaysia. International Journal of Business and Social Science, 6(1), 561-583.

Mohamad, S. A., \& Kassim, S. (2018, December). Examining the Relationship between UTAUT Construct, Technology Awareness, Financial Cost and E-Payment Adoption among Microfinance Clients in Malaysia. In 1st Aceh Global Conference (AGC 2018). Atlantis Press.

Olaleye, S. A., Ukpabi, D., Karjaluoto, H., \& Rizomyliotis, I. (2019). Understanding technology diffusion in emerging markets. International Journal of Emerging Markets, 8(1), 232-265. doi: 10.1108/ijoem-01-20180055

Omotayo, F. O., \& Omotope, A. R. (2018). Determinants of continuance intention to use online shops in Nigeria. Journal of Internet Banking and Commerce, 23(2), 1-48.

Rahman, S., Khan, M. A., \& Iqbal, N. (2018). Motivations and barriers to purchasing online: understanding consumer responses. South Asian Journal of Business Studies, 7(1), 111-128. doi: 10.1108/sajbs-11-20160088

Saunders, M., Lewis, P. \& Thornhill, A. (2016). Research methods for business students $\left(7^{\text {th }}\right.$ ed.). Harlow, England: Pearson Education Ltd.

Salimon, M., Mokthar, S., Yusr, M., Yusoff, R., Kareem, O., \& Bamgbade, J. (2018). Do risk and fun matter in the adoption of mobile commerce in Nigeria? A PLS-SEM approach. Management Science Letters, 8(6), 507518.

Slade, E. L., Dwivedi, Y. K., Piercy, N. C., \& Williams, M. D. (2015). Modelling consumers' adoption intentions of remote mobile payments in the United Kingdom: Extending UTAUT with innovativeness, risk, and trust. Psychology \& Marketing, 32(8), 860-873.

Tandon, U., Kiran, R., \& Sah, A. N. (2016). Understanding online shopping adoption in India: Unified Theory of Acceptance and Use of Technology 2 (UTAUT2) with perceived risk application. Service Science, 8(4), 420437.doi: $10.1287 /$ serv.2016.0154

Tandon, U., Kiran, R., \& Sah, A. N. (2017). The influence of website functionality, drivers and perceived risk on customer satisfaction in online shopping: an emerging economy case. Information Systems and e-Business Management, 16(1), 57-91. doi: 10.1007/s10257-017-0341-3

Taiminen, H. M., \& Karjaluoto, H. (2015). The usage of digital marketing channels in SMEs. Journal of Small Business and Enterprise Development, 22(4), 633-651. doi: 10.1108/jsbed-05-2013-0073\#

Tarhini, A., Masa'deh, R., Al-Busaidi, K. A., Mohammed, A. B., \& Maqableh, M. (2017). Factors influencing students' adoption of e-learning: a structural equation modelling approach. Journal of International 
Education in Business, 10(2), 164-182. doi: 10.1108/jieb-09-2016-0032

Venkatesh, V., Thong, J. Y. L. \& Xu, X. (2012). Consumer acceptance and use of information technology: Extending the Unified Theory of Acceptance and Use of Technology ${ }^{1}$. MIS Quarterly, 36(1), 157-178.

Venkatesh, V. Morris, M. G., Davis, G. B. \& Davis, F. D. (2003). User acceptance of information technology: Toward a unified view. MIS Quarterly, 27(3), 425-478.

Zhu, D. H., Wang, Y. W., \& Chang, Y. P. (2018). The influence of online cross-recommendation on consumers' instant cross-buying intention. Internet Research, 28(3), 604-622. doi: 10.1108/intr-05-2017-0211 